\title{
Avant propos - Changement de millénaire et actualité de la recherche
}

\section{Hugues Hotier}

\section{(2) OpenEdition}

1 Journals

Édition électronique

URL : http://journals.openedition.org/communicationorganisation/2479

DOI : 10.4000/communicationorganisation.2479

ISSN : $1775-3546$

Éditeur

Presses universitaires de Bordeaux

Édition imprimée

Date de publication : 1 mai 2001

ISSN : 1168-5549

Référence électronique

Hugues Hotier, « Avant propos - Changement de millénaire et actualité de la recherche »,

Communication et organisation [En ligne], 19 | 2001, mis en ligne le 27 mars 2012, consulté le 21

septembre 2020. URL : http://journals.openedition.org/communicationorganisation/2479 ; DOI :

https://doi.org/10.4000/communicationorganisation.2479

Ce document a été généré automatiquement le 21 septembre 2020.

(c) Presses universitaires de Bordeaux 


\title{
Avant propos - Changement de millénaire et actualité de la recherche
}

\author{
Hugues Hotier
}

1 C'est fou ce que le changement de millénaire peut stimuler les responsables. Tous les responsables. Je veux dire les responsables de tout, je n'ai pas dit « de tout et n'importe quoi », les responsables. Le mot repentance a été employé à tour de bras comme s'il fallait d'urgence apurer ses comptes et se refaire une virginité pour entrer dans une ère nouvelle. Nous y sommes et, foin de repentance, on recommence à massacrer et à spolier.

2 Les responsables de revues, je n'ai pas dit les meneurs de revue, les responsables de revues scientifiques ont presque tous pensé que le moment était venu de faire le point de la recherche dans la discipline concernée. Pas par souci de repentance. Veuillez ne pas mêler les deux paragraphes. Mais, quand même, comme si on allait entrer dans une ère nouvelle. Les revues de sciences de l'information et de la communication n'ont pas échappé à cet effet d'entraînement. C'est le cas de la nôtre qui vous propose une actualité de la recherche en communication des organisations mais en privilégiant les jeunes chercheurs.

3 Nous avons toujours dit que Communication \& Organisation était un lieu d'accueil et de publication pour les jeunes chercheurs et nous sommes heureux d'en faire la démonstration avec le dossier qu'a coordonné Françoise Bernard, professeur à l'Université d'Avignon.

4 Au moment où vous est livré ce numéro, nous mettons la dernière main au numéro 20. Il n'y a là rien de bien extraordinaire puisque celui que vous avez en mains est le 19. Je voulais seulement souligner combien nous sommes heureux, et fiers avouons le, de célébrer le dixième anniversaire de notre revue que ce vingtième numéro sanctionnera. Rendez-vous en décembre! 